\title{
IDENTIFYING CULTURAL DIFFERENCE IN R\&D PROJECT FOR PERFORMANCE IMPROVEMENT: A FIELD STUDY
}

\author{
S. X. Zeng ${ }^{1}$, X. M. Xie ${ }^{2}$, C. M. Tam ${ }^{3}$, P. M. Sun ${ }^{4}$ \\ 1, 2, 4 Antai School of Economics \& Management, Shanghai Jiaotong University, \\ 535 Fahuazhen Road, Shanghai 200052, China \\ ${ }^{3}$ College of Science and Engineering, City University of Hong Kong, \\ 83 Tat Chee Ave., Kowloon, Hong Kong \\ E-mails: ${ }^{2} z e n g s a i x i n g @ s j t u . e d u . c n ;{ }^{2 x x m 1030 @ 126 . c o m ; ~}{ }^{3}$ bctam@cityu.edu.hk; ${ }^{4}$ pmsun@sjtu.edu.cn \\ Received 1 October 2007; accepted 18 November 2008
}

\begin{abstract}
In recent years, some large multinational companies have begun moving their R\&D centers to China. As a result, cross-cultural management for R\&D projects becomes challenging due to the cultural diversity. Based on the technique of relative importance index (RII), this study examines the gaps between the Chinese and Western cultures in R\&D projects for multinational firms. The findings show there is a significant difference between Chinese and Western cultures. The top five factors transformed into self-reflection statements include: 1) You could accept your manager criticizing your mistake in public; 2) You avoid any conflict with your manager; 3) Objective of the project is the target for the whole project group; 4) You do not mind the methods for your performance evaluation; and 5) You pay greater attention to improve "relationship" among colleagues. Overall, these findings reveal managerial implications for R\&D managers that the need to recognize and manage cultural difference is an important component in cross-cultural project management.
\end{abstract}

Keywords: cultural difference, $R \& D$ project; project management

\section{Introduction}

With the rapid development of a globalized economy, international projects characterized by cross-culture have been unprecedentedly growing (Asgary and Walle 2002; Oertig and Buergi 2006; Zwikael et al. 2005). The essential feature of international project management is the diversity of culture and therefore, it is important to exercise cross-cultural management. Cultural difference is the major factor affecting success or failure of projects (Low and Shi 2001). While some cultures (and individuals) see the difference in a strictly negative light, others see it as a necessary growth procedure (for both individuals and business alike). No matter whether the difference is viewed as desirable or not, the fact is that cultural difference will exist (Darling and Fogliasso 1999; Tsui et al. 2007). When such a cultural difference is recognized and managed in a proper manner, it can lead to innovative business practices, faster and better organizational learning, and sustainable sources of competitive advantages (Bhasin 2007; Hutchings 2003; Magala 2007). For building up awareness and understanding of cultural difference in order to develop effective international management teams, the need to recognize and manage other cultures is an important component in project management in this era of globalization (Hong et al. 2007).

Since the open policy in 1978, China has become one of the largest economies around the world. Along with its entering into WTO, more and more foreign companies, including multinational ones, have started up their business in China and entered the Chinese market (Chen and Partington 2004; Zhou et al. 2005). In recent years, some large multinational companies have begun moving their R\&D centers to China. As a result, cross-cultural management for R\&D projects becomes challenging due to the cultural diversity (Chen and Tjosvold 2005; Cui et al. 2002). Hence, there is a pressing need to understand the Chinese style of management, and the foreign project managers in dealing with projects in China should be adept at cross-cultural management (Garg and Ma 2005).

The objective of this study is to examine the gaps between the Chinese and Western cultures and provide recommendations that could create a better understanding of cultural differences so that an effective management style and approach is deployed in $\mathrm{R} \& \mathrm{D}$ projects by multinational firms. 


\section{Previous study}

Hofstede $(1980,1991)$ defined culture as a collective phenomenon, because it was at least partly shared with people who live or lived within the same social environment, where it was learned. Trompenaars (1993) agreed that culture was based on languages, economy, religion, policies, social institutions, class, values, status, attitudes, manners, customs, material items, aesthetics and education, which subsequently influenced managerial values. Berthons (1993) viewed culture as the results of the human actions and showed the link between the ideas of mental programming and the consequence of behaviour derived from this.

Cultural difference arises due to a variety of factors. Individual differences in goals, expectations, values, proposed courses of action, and suggestions about how to best handle a situation, are unavoidable (Darling and Fogliasso 1999). In a cross-cultural organization, changes in personnel, clientele, product line, financial climate, and even corporate philosophy and/or vision will happen. Project managers, who want to transcend state, regional, national cultural and organizational industrial boundaries in today's global economy, need to develop flexible and new coping skills to continue functioning in a positive, productive way in the midst of these sometimes unsettling events (Ramaprasad and Prakash 2003). Cross-cultural awareness facilitates successful performance of a set task.

Swierczek (1994) discusses issues relating to managing cultural difference in projects such as international joint ventures. He presented comparative findings from a case study of mono-cultural groups such as Malaysian, Thai and French managers, and multicultural groups of European and Asian managers. Exploring the development of the project culture in the project life cycle, Marrewijk (2007) suggested the necessity for project managers and project performing organizations to reflect upon the development of the project culture during the project life cycle.

Zwikael et al. (2005) examined differences in project management style between two different cultures: the Japanese and the Israelis. Significant cultural differences were found between the two countries. They found that Israeli project managers were more focused on performing "scope" and "time" management processes, while formal "communications" and "cost" management were more frequently used by Japanese project managers. Japanese organizations used clear and measurable success measures for each project, while project objectives in Israeli organisations were often quite foggy.

Using a sample of workgroup personnel for new product development in New Zealand, the western cultural environment, and Singapore, Garrett et al. (2006) measured national culture and determined the applicability of different organization integration mechanisms. Results show key differences between the two samples, indicating a link between formalization, centralization, role flexibility and interfunctional climate mechanisms with the Hofstede dimensions of Power Distance, Masculinity and Uncertainty Avoidance of national culture. Using managerial competency assessment method, Chong (2008) appraised managers from four East Asian countries and managers from the United States. He found that the assessed competencies of managers from the different nationalities were subject to cultural factors that shaped personality and behavioural choices.

Some researchers address the difference between Chinese culture and others. Chen and Partington (2004) reported an empirical comparison of matched samples of Chinese and Western construction project managers' conceptions of their work. Fundamental differences in conception of the meaning and significance of different forms of relationship were highlighted in construction project management that had implications for practice. Using a real-life case study of the New Chinese Hotel project in China, they examined how the interaction between cross-cultural management and construction project management could affect the outcome of a project.

Lin (2004) examined cultural adaptive behaviour in international joint ventures, its key relationship contexts (e.g. relationship commitment and relative dependence), and influence of national culture. He found that cultural adaptation was driven by relationship commitment and relative dependence of both Chinese and US joint venture partners. More recently, Hong et al. (2007) examined the cross-cultural influences on organizational learning in multinational companies (MNCs). They conducted a study at five Japaneseinvested manufacturing companies in the Pearl River Delta, China. Their research found that managers perceived Chinese frontline workers as lacking constructive engagement and member solidarity as compared with their Japanese counterparts, thus limiting organizational learning, and attributed these perceived differences to deep-seated cultural values. 


\section{Methods of study for this research}

\subsection{Data collection}

In order to understand cultural difference and its influence in R\&D project at multinational firms in China, a questionnaire survey was conducted during the period of January 2007 to May 2007. Thirty questions used in the questionnaire were determined from relevant literature. Five hundred questionnaires were sent to employees engaged in relevant project management teams involved in product development in foreign-invested enterprises, which is listed in "Directory of Foreigninvested Enterprises in China".

A total of 94 questionnaires were received. Table 1 shows that the 94 respondents are composed of 36 Chinese $(38.3 \%)$ and 58 foreigners $(61.7 \%)$. The latter includes $53(56.4 \%)$ people from the western countries. Among the 94 respondents, 76 (80.9\%) were directly involved in R\&D work, 7 (7.4\%) responsible for human resources management, 7 (7.4\%) for logistic service, and $3(3.2 \%)$ in the other category. 64 respondents $(68.1 \%)$ claimed that they had experience in project management of over five years, and $30(31.9 \%)$ between three and five years, which suggests a good validity of their responses.

Table 1. Characteristics of the respondents

\begin{tabular}{lcc}
\hline Characteristics & Number & Percentage \\
\hline Nationality of Respondents & & \\
• Chinese & 36 & 38.3 \\
• Foreigners & 58 & 61.7 \\
Total & 94 & 100 \\
\hline Functions & & \\
- R\&D & 76 & 80.9 \\
• Human Resources & & \\
$\quad$ Management & 7 & 7.4 \\
- Logistic Service & 7 & 7.4 \\
- Others & 3 & 3.2 \\
Total & 94 & 100 \\
\hline Experience Level (year) & & \\
• >5 & 64 & 68.1 \\
• 3-5 & 30 & 31.9 \\
Total & 94 & 100 \\
\hline
\end{tabular}

\subsection{Methodology}

To determine the relative rankings of the cultural gaps of the identified factors, relative importance index (RII) was employed. The respondents were asked to rank the listed factors based on their relative importance using scores ranging from 1 to 5 , where ' 1 ' represents the least important and ' 5 ' stands for the most important. The scores were then transformed to relative importance index (RII) using equation (1). Calculated RII values fall into the range of 0 and 1 .

$$
\text { Relative importance index }=\frac{\sum w}{A^{*} N},
$$

where: $w$ is the score given to a factor by a respondent, ranging from 1 to 5 ; $A$ is the highest score (i.e. 5 in the study) and $N$ is the total number of respondents.

Then the difference of RII between the Chinese and foreign respondents was calculated using equation (2).

$$
\text { D_RII }=\mid \text { RII_CR }- \text { RII_FR } \mid \times 100 \text {. }
$$

where: D_RII is the difference of RII between the Chinese and foreign respondents revealing the cultural difference in the project team; RII_CR is the relative importance index for one factor collected from the Chinese respondents; and RII_FR from the foreign respondents.

\section{Results and analysis}

\subsection{Cultural difference}

Based on equation (1), RII from the Chinese respondents (RII_CR) and the foreign respondents (RII_FR) were calculated and listed in Table 2 .

Using equation (2), the identified factors in a form of self-reflection statements are ranked according to the values of D_RII that can reveal the cultural difference in project management of $R \& D$ projects. The result is shown in Table 3.

Table 3 reveals that there is an obvious cultural difference in project management. The factor "You could accept your manager criticizing your mistake in public" was ranked first with a D_RII of 38.3. In Chinese culture, "Mianzi" is the Chinese concept of giving "face". This translates into giving one's respect and recognizing the status and moral reputation in public, indeed enhancing this status by whatever ways possible. It is important to protect one's "face" but it is perhaps even more important to give "face" to others (Buttery and Leung 1998). To "give face" means to give praise to someone in an organization. To get someone to "lose face" is to denounce his status or reputation. 
Table 2. RII from Chinese respondents and foreign respondents

\begin{tabular}{|c|c|c|}
\hline Factors & RII_CR & RII_FR \\
\hline The government's attitude is important for the smooth start-up of a project. & 0.635 & 0.716 \\
\hline You do not mind the methods used for your performance evaluation. & 0.733 & 0.555 \\
\hline Relying on manager's opinion in running projects means incompetent. & 0.537 & 0.477 \\
\hline Your manager always pays attention to your progress. & 0.698 & 0.684 \\
\hline Projects supported by the government have more chance to be successful. & 0.581 & 0.497 \\
\hline You spend a lot of time on communication. & 0.667 & 0.523 \\
\hline You attend project meetings on time. & 0.876 & 0.897 \\
\hline New employee needs at least half a year to adapt to the work. & 0.571 & 0.535 \\
\hline You feel that the balance of schedule, cost and quality has been done very well. & 0.441 & 0.439 \\
\hline You avoid any conflict with your manager. & 0.695 & 0.381 \\
\hline You try hard to improve relationship among colleagues. & 0.460 & 0.632 \\
\hline You could accept your manager criticizing your mistake in public. & 0.378 & 0.761 \\
\hline In running project, language communication is an obstacle. & 0.746 & 0.723 \\
\hline You are quite familiar with competitors' similar products. & 0.670 & 0.748 \\
\hline You prefer to cooperate with people with similar cultural background. & 0.705 & 0.806 \\
\hline You can adapt to an unfamiliar environment quickly. & 0.686 & 0.742 \\
\hline It is necessary for your project leader to prepare a definitive working schedule for you. & 0.654 & 0.703 \\
\hline All your team members try their best to run the project. & 0.752 & 0.742 \\
\hline Project scope statements can be modified according to customer's new request. & 0.711 & 0.658 \\
\hline You like to do works with a clear definition of scope. & 0.695 & 0.568 \\
\hline In resource allocation, project managers would consider your opinions. & 0.590 & 0.555 \\
\hline The whole project group agrees that achievement of the objective of a project is their common target. & 0.746 & 0.516 \\
\hline Contract management is important for $\mathrm{R} \& \mathrm{D}$ projects. & 0.562 & 0.523 \\
\hline You must finish one task on hand before you start a new task. & 0.514 & 0.548 \\
\hline It is common for the actual cost of a project exceeding the planned budget for R\&D projects. & 0.584 & 0.548 \\
\hline The difference in legal systems in different countries will create problems. & 0.565 & 0.568 \\
\hline Execution of projects must follow the original plan strictly. & 0.848 & 0.826 \\
\hline Specific quality standard is important for $\mathrm{R} \& \mathrm{D}$ projects. & 0.863 & 0.865 \\
\hline You like to face a new challenge every day. & 0.750 & 0.813 \\
\hline Personal achievement is more important than team success. & 0.727 & 0.806 \\
\hline
\end{tabular}

The concept of corporate reputation is relatively new to many Chinese organizations. Personal reputation, on the other hand, has been well acknowledged. Traditional Chinese culture places a great emphasis on its association with a set of core values: virtue, moral consciousness, integrity, trustworthiness, the sense of shame and the fear of "loss of face" (Fan 2000; Ba- tonda and Perry 2003). As Yang (1989) indicated, it is very important for Chinese people to have harmony maintenance, impression management, face protection, social acceptance and avoidance of punishment, embarrassment, conflict, rejection, ridicule and retaliation in a social situation. It represents a tendency for the Chinese to act in accordance with external expecta- 
Table 3. Ranking of factors revealing the cultural difference

\begin{tabular}{|c|c|c|}
\hline Ranking & Factors & D_RII \\
\hline 1 & You could accept your manager criticizing your mistake in public. & 38.3 \\
\hline 2 & You avoid any conflict with your manager. & 31.4 \\
\hline 3 & The whole project group agrees that achievement of the objective of a project is their common target. & 23.0 \\
\hline 4 & You do not mind the methods used for your performance evaluation. & 17.8 \\
\hline 5 & You try hard to improve relationship among colleagues. & 17.2 \\
\hline 6 & You spend a lot of time on communication. & 14.4 \\
\hline 7 & You like to do works with a clear definition of scope. & 12.7 \\
\hline 8 & You prefer to cooperate with people with similar cultural background. & 10.1 \\
\hline 9 & Projects supported by the government have more chance to be successful. & 8.4 \\
\hline 10 & The government's attitude is important for the smooth start-up of a project. & 8.1 \\
\hline 11 & Personal achievement is more important than team success. & 7.9 \\
\hline 12 & You are quite familiar with competitors' similar products. & 7.8 \\
\hline 13 & You like to face a new challenge every day. & 6.3 \\
\hline 14 & Relying on your manager's opinion in running projects means incompetent. & 6.0 \\
\hline 15 & You can adapt to an unfamiliar environment quickly. & 5.6 \\
\hline 16 & Project scope statements can be modified according to customer's new request. & 5.3 \\
\hline 17 & It is necessary for your project leader to prepare a definitive working schedule for you. & 4.9 \\
\hline 18 & Contract management is important for R\&D projects. & 3.9 \\
\hline 19 & It is common for the actual cost of a project exceeding the planned budget for R\&D projects. & 3.6 \\
\hline 20 & New employee needs at least half a year to adapt to the work. & 3.6 \\
\hline 21 & In resource allocation, project managers would consider your opinions. & 3.5 \\
\hline 22 & You must finish one task on hand before you start a new task. & 3.4 \\
\hline 23 & In running project, language communication is an obstacle. & 2.3 \\
\hline 24 & Execution of projects must follow the original plan strictly. & 2.2 \\
\hline 25 & You attend project meetings on time. & 2.1 \\
\hline 26 & Your manager always pays attention to your progress. & 1.4 \\
\hline 27 & All your team members try their best to run the project. & 1.0 \\
\hline 28 & The difference in legal systems in different countries will create problems. & 0.3 \\
\hline 29 & You feel that the balance of schedule, cost and quality has been done very well. & 0.2 \\
\hline 30 & Specific quality standard is important for R\&D projects. & 0.2 \\
\hline
\end{tabular}

tions or social norms. The need to maintain "face" in public also serves as a negative force for complaint behavior because not getting a satisfactory result from the complaint means losing "face" in front of people, even if these people are not significant to them (Lowe and Corkindale 1998; Yang 1989).
The factor "You avoid any conflict with your manager" was ranked second, with a D_RII of 31.4. That could reflect the cultural difference of collectivist belief in China and individualist in the West. Chinese collectivism, harmony, out-directed and relationship culture may have implications for Chinese ways of experiencing and resolving conflicts. Chinese employees are 
likely to pay greater attention to group harmony and relationship with all involved when resolving conflicts. They would try to avoid direct debates or confrontation and always try to get through conflicts quietly. In contrast, Western employees may encourage open discussion, and the use of disagreements and conflicts in order to get problems solved quickly (Chen et al. 2005; Hoon-Halbauer 1999).

The factor "The whole project group agrees that achievement of the objective of a project is their common target" was graded third, with a D_RII of 23.0. That demonstrates the major cultural difference between the Chinese and Westerners. In collectivist China, employees' personal goals are subordinate to the goals of the organization (Lin 2004). As people's selfidentity derives and is enhanced from group membership, the concern for the consequences of their actions for the company arguably leads to greater emotional dependence on the company. In the individualist Western world, emphasis is placed on individual freedom and preferences, and individual self-identity derives and is enhanced from self-sufficiency and self-pursuit of goals (Chen and Partington 2004; Jaw et al. 2007). The factor "You do not mind the methods used for your performance evaluation" was ranked fourth, with a D_RII of 17.8. As Zhou et al. (2005) indicated, American companies and European companies prefer all-perspective performance evaluation. American companies like to evaluate someone's performance by a group of staff members and one's superior to avoid impartial evaluation results. The superior will observe the employee's behavior in daily work while other staff members could evaluate the performance based on facts instead of comments. Such way of mutual evaluation will reduce the influence of personal bias. In European companies, an employee will be evaluated by colleagues, in, however, an anonymous manner, which can also reduce the influence of Mianzi.

The factor "You try hard to improve relationship among colleagues" was graded fifth, with a D_RII of 17.4. In Chinese, "Guanxi" denotes "connections" or "a relationship", which is a concept not easily understood by Westerners. It stands for a network of relationships among various parties that work together and support one another. In the old days when Westerners started doing business with the Chinese, it was described as "a special relationship between a person who needs something and a person who has the ability to give something". "Guanxi" represents in fact a system that is essential to the survival and prosperity of groups of people within the Chinese community who cannot enjoy any benefits from the politics. "Guanxi" has an impact on almost every individual and every aspect of the Chinese society. It is important to understand that "Guanxi" is not one-off but rather a life-long relationship. Good "Guanxi" establishes close and friendly relationships on the basis of emotional ties, trust and long-term mutual benefits.

The factors "You spend a lot of time on communication" and "You prefer to cooperate with people with similar cultural background" were graded sixth and eighth respectively, with D_RII of 14.4 and 10.1. Communication is critical to effective R\&D (Mendez 2003). In cross-cultural management, certain forms of communication are acceptable in one country while these may be considered taboo in another. Managers should also be sensitive to the non-verbal signals, as they may carry a significant meaning, which, when perceived wrongly, may create a harmful effect. For example, Westerners may not be comfortable with silence and reticence; taking time for reflection is often seen as evidence of ineffectiveness. While direct physical contacts (for example, a peck on the cheek) may be practiced by North Americans, which, however, are not acceptable in most Asian countries. The Chinese avoid using language which may cause offence. A study by Ngowi (1997) found that innovation was inhabited in project team from different cultural background compared to projects in which the teams had a similar cultural background.

The factor "You like to do works with a clear definition of scope" was ranked the seventh, with a D_RII of 12.7. In fact, uncertainty avoidance is one of the Chinese cultural dimensions. The Chinese opt to build strong personal relationships with business partners to avoid uncertainty or risk (Batonda and Perry 2003; Richards and Yang 2007). However, the R\&D activity is characterized by rapidly changing technological conditions and low-defined job descriptions. Furthermore, strong centralization together with formalized definition of scopes often leads to inflexibility which is opposed to the best conditions for the R\&D process (Mendez 2003).

The factors "Projects supported by the government have more chance to be successful" and "The government's attitude is important for the smooth start-up of a project" were ranked ninth and tenth. In China, the government plays an important role in approving projects, allocating resources, and arranging finance (Luo 2001). For multinational corporations, the skills of managing corporate-government relations and communications are essential (Fan 2007). 


\subsection{Influence of cultural difference on team performance}

In our study, the life cycle of team development for $\mathrm{R} \& \mathrm{D}$ project was decomposed into six stages, including collection, entrenchment, resolution/accommodation, synergy, decline, and break-up (Eskerod and Blichfeldt 2005; Maylor 2003). Of all the respondents, $61 \%$ claimed that the influence of cultural difference could permeate into the team development life cycle in $R \& D$ projects. With respect to the influence on each stage of the life cycle, the respondents indicated a marked difference in their evaluation (Fig. 1).

As shown in Fig. 1, the relative influence of cultural difference along the life cycle stages of team development shows a U-shaped curve. At the start-up of team development, the influence of cultural difference is significant in the collection (31\%) and entrenchment $(30 \%)$ stages. That could be reflected from the three main factors aforementioned, including "You try hard to improve relationship among colleagues", "You spend a lot of time on communication", and "You prefer to cooperate with people with similar cultural background". Culture in terms of language differences, demeanor, values and norms slows down interactions among people. This is particularly problematic during the early stages of a team development life cycle when differences create misunderstandings which is timeconsuming to resolve. Sometimes cultural differences create uncertainty in the team development agenda since people are not sure whether they should make themselves clearer or if they could fully understand others (Chevrier 2003). This can result in unintended consequences such as dislike and distrust among members that hinders the formation of a common understanding of the problem (Schweiger et al. 2003).

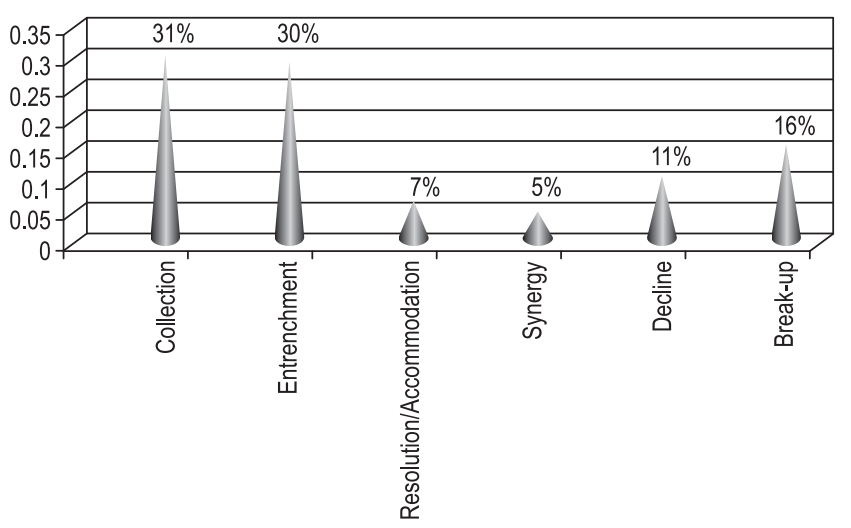

Fig. 1. Influence of cultural difference on stages in life cycle of team development
As R\&D works are increasingly affected by constraints such as costs, quality and deadlines, it is important to highlight team performance within a cross-cultural project group under these constraints. The respondents were requested to assess team performance at each stage of team development life cycle, and the results are shown in Fig. 2.

Fig. 2 shows an inverted U-shaped curve of team performance along the life cycle stages of team development. In fact, cultural difference undoubtedly affects team performance (Chevrier 2003). In our survey, it is found that there exists obvious cultural difference due to the eight factors with D_RII larger than 10, including "You could accept your manager criticizing your mistake in public", "You avoid any conflict with your manager", "The whole project group agrees that achievement of the objective of a project is their common target", "You do not mind the methods used for your performance evaluation", "You try hard to improve relationship among colleagues", "You spend a lot of time on communication", "You like to do works with a clear definition of scope" and "You prefer to cooperate with people with similar cultural background". Hence, the factor "You prefer to cooperate with people with similar cultural background" reflects the team members' choice. With the advancement of a R\&D project, team members will gradually become acquainted with the project goals and mission, and the cultural difference will start to decrease, thus enabling them to make the right choices and decisions during the project (Eskerod and Blichfeldt 2005). Team performance has been obviously improved in the stages of resolution/accommodation and synergy. That is reflected from the three factors with little difference, e.g. "Execution of projects must follow the original plan strictly", "All your team members try their best to run

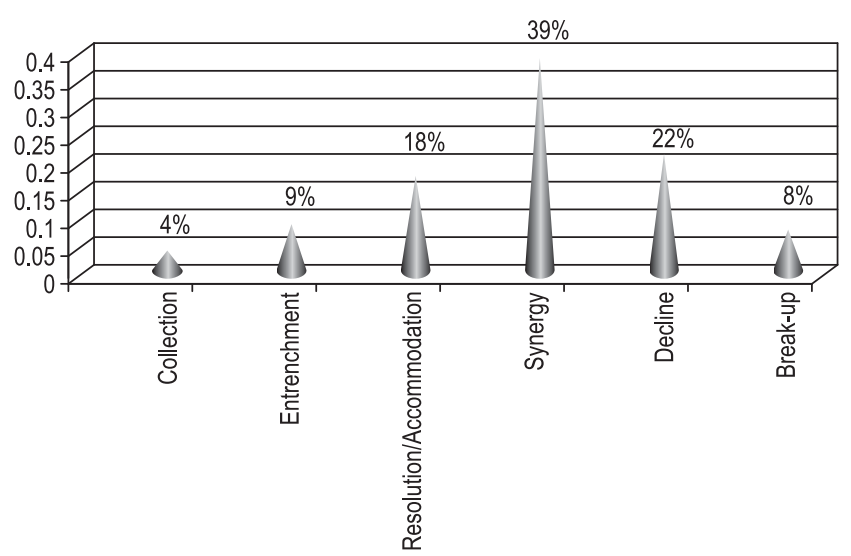

Fig. 2. Relation between R\&D performance and life cycle of team development 
the project", and "You feel that the balance of schedule, cost and quality has been done very well."

Previous studies also support the performance pattern along the life cycle. Watson et al. (1993) conducted a survey to measure the interaction process and performance of culturally homogeneous and culturally diverse groups. He found that homogeneous groups initially scored higher on both process and performance effectiveness. Over time, both types of groups showed improvement on process and performance, and the between-group differences converged (Watson et al. 1993). Hence, it is important to encourage and provide time for team members to discuss how the R\&D process is going and to decide on a plan of action for increasing their problem-solving ability in managing culturally diverse groups.

\section{Conclusions}

The challenge of international project management is sustainably delivering projects within a context of diversity of cultures and therefore, cross-cultural management is crucial to project management success. Cultural difference is the major factor affecting success or failure of projects. In recent years, some large multinational companies have begun transferring their R\&D centers to China. Cross-cultural management for R\&D projects is not an easy task, as there are significant barriers to developing an effective relationship between employees with cultural diversity. Hence, there is a pressing need to understand the cultural diversity and exercise proper measures to manage it. Foreign project managers dealing with projects in China should be adept in cross-cultural management. Using a structured questionnaire survey, this paper explores the difference between Chinese and Western cultures in running international $R \& D$ projects. It is found that there is a significant difference between Chinese and Western cultures. The top five factors transformed from self-reflection statements explored through this research include:

- You could accept your manager criticizing your mistake in public;

- You avoid any conflict with your manager;

- The whole project group agrees that achievement of the objective of a project is their common target;

- You do not mind the methods used for your performance evaluation; and

- You try hard to improve relationship among colleagues.

When these cultural divergences are defined, co-workers from different cultural background can be more appreciative to one another. Management can then harness these differences to achieve synergy and performance improvement in project management.

Finally, the following suggestions/recommendations are intended to assist R\&D managers to recognize and manage cultural differences in cross-cultural project management:

- To succeed internationally for project management, cultural sensitivity, meaning a sense of empathy, flexibility and creativity informed by cultural knowledge should be required. On the one hand, it should invest heavily in providing cultural sensitivity training to address issues such as etiquette, protocol, communication styles and negotiation approaches. On the other hand, cross-cultural training should be provided for staff, such as language training, case studies, cross-cultural learning, and the capability of adaptation to local social and cultural environment.

- Cultural collaborative mechanism should be established through effective cross-cultural communication. At first, third cultural values should be created by identifying cultural similarities and differences, and by respecting diverse cultures as well as values. Then, cross-cultural difference should be integrated with the common rules of conduct and team values and learning from each other.

- As cross-cultural project team at different stages of the life cycle presents various cultural features, different strategies should be adopted in the process of cross-cultural management according to the different characteristic of life-cycle of R\&D projects.

- As co-workers of R\&D projects come from different countries with different faiths, cultures, world views and experiences, which results in cultural conflict in cross-cultural management, it is necessary for project team to set up a project management system characterized by a common management culture to overcome the cultural differences due to the different understanding of culture, and to establish crosscultural communication channels.

\section{Acknowledgement}

The authors gratefully acknowledge the respondents who contributed to this research. This study is supported by the National Natural Science Foundation of China (No.70772067), the Education Ministry of China (No.NCET-06-410) and the Shuguang Planning of Shanghai Education Development Foundation (No.06SJ17). 


\section{References}

Asgary, N. and Walle, A. H. 2002. The cultural impact of globalization: economic activity and social change, Cross Cultural Management: An International Journal 9(3): 58-75.

Batonda, G. and Perry, C. 2003. Influence of culture on relationship development processes in overseas Chinese/Australian networks, European Journal of Marketing 37(11/12): 1547-1574.

Berthons, P. R. 1993. Psychological type and corporate culture: relationship and dynamics, Omega 21: 329-344.

Bhasin, B. B. 2007. Succeeding in China: cultural adjustments for Indian businesses', Cross Cultural Management 14(1): 43-53.

Buttery, E. A. and Leung, T. K. P. 1998. The difference between Chinese and Western negotiations, European Journal of Marketing 32(3/4): 374-389.

Chen, P. and Partington, D. 2004. An interpretive comparison of Chinese and Western conceptions of relationships in construction project management work, International Journal of Project Management 22(5): 397-406.

Chen, Y. F. and Tjosvold, D. 2005. Cross-cultural leadership: Goal interdependence and leader-member relations in foreign ventures in China, Journal of International Management 1(3): 427-439.

Chen, Y. F.; Tjosvold, D.; Fang, S. S. 2005. Working with foreign managers: Conflict management for effective leader relationships in China, International Journal of Conflict Management 16(3): 265-286.

Chevrier, S. 2003. Cross-cultural management in multinational project groups, Journal of World Business 38: 141-149.

Chong, E. 2008. Managerial competency appraisal: A crosscultural study of American and East Asian managers, Journal of Business Research 61(3): 191-200.

Cui, C. C.; Ball, D. F.; Coyne, J. 2002. Working effectively in strategic alliances through managerial fit between partners: some evidence from Sino-British joint ventures and the implications for R\&D professionals, $R \& D$ Management 32(4): 343-357.

Darling, J. R. and Fogliasso, C. E. 1999. Conflict management across cultural boundaries: a case analysis from a multinational bank, European Business Review 99(6): 383-392.

Eskerod, P. and Blichfeldt, B. S. 2005. Managing team entrees and withdrawals during the project life cycle, International Journal of Project Management 23: 495-503.

Fan, Y. 2000. A classification of Chinese culture, Cross Cultural Management 7(2): 3-10.

Fan, Y. 2007. "Guanxi”, government and corporate reputation in China: Lessons from international companies, Marketing Intelligence and Planning 25(5): 499-510.

Garg, R. K. and Ma, J. 2005. Benchmarking culture and performance in Chinese organization, Benchmarking 12(3): 269-274.
Garrett, T.; Buisson, D. H.; Yap, C. M. 2006. National cultural and $\mathrm{R} \& \mathrm{D}$ and marketing integration mechanisms in new product development: A cross-cultural study between Singapore and New Zealand, Industrial Marketing Management 35(3): 293-307.

Hofstede, G. 1980. Culture's consequences: international differences in work-related values. Newbury Park, CA: Sage.

Hofstede, G. 1991. Culture and organizations. Maidenhead, UK: McGraw Hill.

Hong, J. F. L.; Snell, R. S.; Smith, M. E. 2007. Cross-cultural influences on organizational learning in MNCS: The case of Japanese companies in China, Journal of International Management 12(4): 408-429.

Hoon-Halbauer, S. K. 1999. Managing relationships within Sino-Foreign joint ventures, Journal of World Business 34(4): 344-371.

Hutchings, K. 2003. Cross-cultural preparation of Australian expatriates in organizations in China, Asia Pacific Journal of Management 20(3): 375-396.

Jaw, B. S.; Ling, Y. H.; Wang, C. Y. P.; Chang, W. C. 2007. The impact of culture on Chinese employees' work values, Personnel Review 36(5): 763-780.

Lin, X. H. 2004. Determination of cultural adaptation in Chinese-U.S. ventures, Cross-cultural Management 11(1): $35-47$.

Luo, Y. 2001. Toward a cooperative view of MNC-host government relations: building blocks and performance implication, Journal of International Business Studies 32(3): 401-420.

Low, S. P. and Shi, Y. Q. 2001. Cultural influence on organizational process in international projects: two case studies, Work Study 50(7): 276-285.

Lowe, A. C. T. and Corkindale, D. 1998. Difference in "cultural values" and their effects on responses to marketing stimuli, European Journal of Marketing 38(9/10): 843-867.

Magala, S. 2007. Manageable inequalities (theoretical landscaping of cross-cultural studies), European Journal of International Management 1(1/2): 56-68.

Marrewijk, A. V. 2007. Managing project culture: The case of Environ Megaproject, International Journal of Project Management 25(3): 290-299.

Maylor, H. 2003. Project management. Third Edition. Great Britain: Pearson Education.

Mendez, A. 2003. The coordination of globalized R\&D activities through project teams organization: an exploratory empirical study, Journal of World Business 38: 96-109.

Ngowi, A. B. 1997. Impact of culture on construction procurement, Journal of Construction Procurement 3(1): 3-15.

Oertig, M. and Buergi, T. 2006. The challenge of managing cross-cultural virtual project teams, Team Performance Management 12(1/2): 23-30. 
Ramaprasad, A. and Prakash, A. N. 2003. Emergent project management: how foreign managers can leverage local knowledge, International Journal of Project Management 21(3): 199-205.

Richards, M. and Yang, Y. 2007. Determinants of foreign ownership in international R\&D joint ventures: Transaction costs and national culture, Journal of International Management 13(2): 110-130.

Schweiger, D. M.; Atamer, T.; Calori, R. 2003. Transnational project teams and networks: making the multinational organization more effective, Journal of World Business 38: 127-140.

Swierczek, F. W. 1994. Culture and conflict in joint ventures in Asia, International Journal of Project Management 12(1): $39-47$.

Trompenaars, F. 1993. Riding the waves of culture: Understanding cultural diversity in business. London: Economist Books.
Tsui, A. S.; Nifadkar, S. S.; Ou, A. Y. 2007. Cross-national, cross-cultural organizational behavior research: Advances, gaps, and recommendations, Journal of Management 33(3): 426-478.

Watson, W. E.; Kumar, K.; Michaelsen, L. K. 1993. Cultural diversity's impact on interaction process and performance: Comparing homogeneous and diverse task groups, Academy of Management Journal 36: 590-602.

Yang, C. F. 1989. A conception of Chinese consumer behavior, in Yang, C. F.; Ho, S. C.; Yau, H. M. (Eds.). Hong Kong Marketing Management at the Cross-Roads, Commercial Press, Hong Kong, NY, 317-342.

Zhou, Y. Q.; Lu, L.; Jiang, B. 2005. Study on staff management practice of multinational company affiliates in China, Management Decision 43(4): 516-522.

Zwikael, O.; Shimizu, K.; Globerson, S. 2005. Cultural difference in project management capabilities: A field study, International Journal of Project Management 23(6): 454-462. 